\title{
Identification of Different Class of Drugs causing Medication Related Problems in the Elderly Patients of Dakshina Kannada
}

\author{
Abhishek Pradhan ${ }^{1}$, Febin Benny ${ }^{2}$, A.R Shabaraya ${ }^{3}$ \\ ${ }^{1}$ Asst. Professor, Department of Pharmacy Practice, Srinivas College of Pharmacy, Mangalore, Karnataka, \\ India - 574143 . \\ ${ }^{2}$ Student, Department of Pharmacy Practice, Srinivas College of Pharmacy, Mangalore, Karnataka, India - \\ 574143. \\ ${ }^{3}$ Professor \& Head, Department of Pharmacy Practice, Srinivas College of Pharmacy, Mangalore, Karnataka, \\ India - 574143 .
}

Corresponding Author: Febin Benny

\begin{abstract}
Medication related problems (MRPs) can be defined as an event or situation involving drug therapy that potentially interferes with desired health outcome.

The aim of the study was to identify the class of drugs that are commonly causing medication related problems in elderly patients. This study was conducted in 150 patients aged over 60 years for a duration of six months. The data were collected using a patient interview form and was analysed using Microsoft Excel 2016.

Out of 150 patients participated in the study, 107 patients were identified with MRPs. And a total of 196 MRPs were identified from those 107 patients. The patients who were treated with cardiovascular agents where more prone to medication related problems and was found to be $57 \%$. They were followed by endocrine agents (33\%), gastro-protectants (21\%), respiratory agents $(17 \%) \&$ others.

This study concluded that, pharmacist can be helpful in identification and prevention of MRPs leading to better healthcare outcomes.
\end{abstract}

Keywords: Medication related problem, elderly population, class of drug

\section{INTRODUCTION}

The PCNE defines medication related problems as "an event or circumstance involving drug therapy that actuality or potentially interferes with desired health outcomes". ${ }^{[1-3]}$ The term "elderly" refers to patients aged over 60 years or over. The elderly represents $21 \%$ of the population \& consume over one third of the prescription drugs. ${ }^{[4,5]}$

According to the 2011 census reports, the elderly population in India was 104 million and it has been projected that by the year 2050, it would rise to 324 million. [6]

According to the Hepler-Strand classification, MRP can be classified into 8 categories- untreated indication, improper drug selection, sub-therapeutic dosage, failure to receive drugs, over dosage, adverse drug reaction, drug interaction and drug use without indication.

MRPs are $4^{\text {th }}-6^{\text {th }}$ leading cause of death in US. ${ }^{[7]}$ From prescribing phase to dispensing phase, MRPs can occur during any phase during the medication use. Improper or incomplete history collection, lack of patient follow up, lack of continuity of care and discontinuity of medication, all may lead to MRPs. ${ }^{[8-10]}$

MRPs are also associated with risk of hospital re-admission, morbidity \& mortality as elderly patients is associated with co-morbidities and use of multiple drugs. [11, 12] Therefore, this study was focused on identifying the class of drugs 
commonly causing MRPs in the elderly population.

\section{MATERIALS \& METHODS}

The present study was a community based observational study and was carried out in different regions of Dakshina Kannada District. The study was done in a population of 150 patients aged above 60 years and was conducted for a duration of 6 months. Ethical clearance was obtained from the Institutional Ethics Committee (IEC) of Srinivas Institute of Medical Science \& Research Centre (SIMS \& RC), Mukka, Mangaluru.

Patients of both sexes above 60 years of age, patient with any illness, on multiple medications, who were willing to participate in the study and met the inclusion criteria, were included in the study. The rest of the patients who were less than 60 years of age, diagnosed with cancer, who were bedridden, who were not willing to participate in the study and met the exclusion criteria were excluded from the study.

The data for the study were collected using a structured data collection form. The data collected included patient's demographic details, personal history, medical \& medication history, current diagnosis \& drug therapy details \& any problems that were experienced/observed by the patient during the course of the treatment.

Statistical Analysis: Microsoft Excel 2016 was used for the data analysis.

\section{RESULT}

\section{Demographic Details}

A total of 150 elderly patients (aged above 60 years old) were enrolled in the study. Patient details along with their medical history were collected with the help of patient interview form. Out of 150 patients, 82 were males and 68 were females. Out of the total population, 76 belonged to the age group between 60-70 years, 56 belonged to the age group between $70-80$ years and 18 were aged above 80 years. The demographic details of the participants have been shown in detail in Table 1 and Figure 1 shows the population participated in the study.

Table 1. Demographic details of the participants

\begin{tabular}{|l|l|l|l|}
\hline Variable & Category & Frequency N=150 & Percentage \\
\hline \multirow{3}{*}{ AGE } & $60 \leq X>70$ & 76 & $51 \%$ \\
& $70 \leq X>80$ & 56 & $37 \%$ \\
& $\geq 80$ & 18 & $12 \%$ \\
\hline \multirow{2}{*}{ GENDER } & Male & 82 & $54 \%$ \\
& Female & 68 & $46 \%$ \\
\hline
\end{tabular}

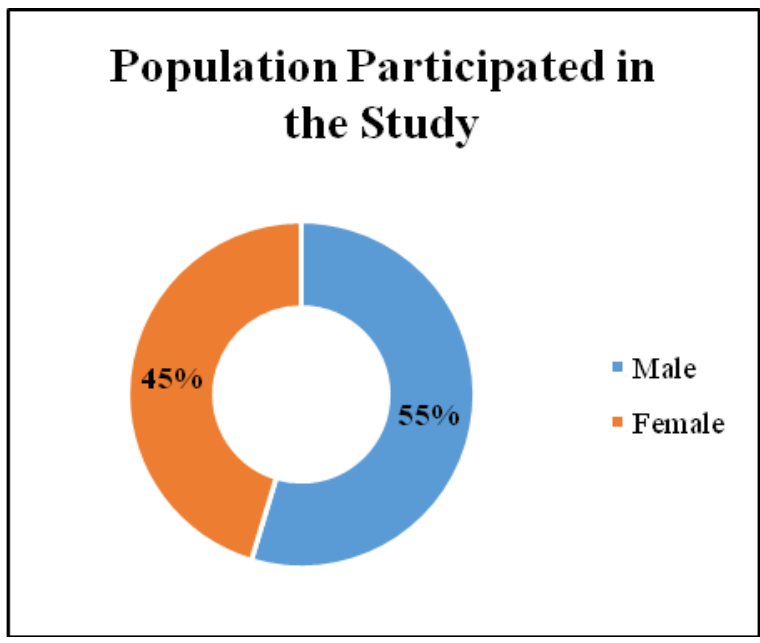

Figure 1. Population participated in the study

\section{Occurrence of MRPs:}

Out of the 150 participants, 107 of them were identified to have MRPs. Among them 56 were males and 51 were females. A total of 196 MRPs were identified from these 107 patients. Figure 2 shows the occurrence of MRPs in the study population. Table 2 shows the occurrence of MRPs among male and female population.

Table 2. Occurrence of MRPs among male and female population.

\begin{tabular}{|l|l|l|l|l|l|l|}
\hline No. & Population & $\begin{array}{l}\text { Total no. Of } \\
\text { participants } \\
\mathbf{N = 1 5 0}\end{array}$ & $\begin{array}{l}\text { Patients identified with MRP's } \\
(\mathbf{n = 1 0 7})\end{array}$ & $\begin{array}{l}\text { Percentage of MRP occurrence in } \\
\text { population }\end{array}$ \\
\hline 1 & Male & 82 & 56 & $68.29 \%$ & $75 \%$ \\
\hline 2 & Female & 68 & 51 & & 7 \\
\hline
\end{tabular}




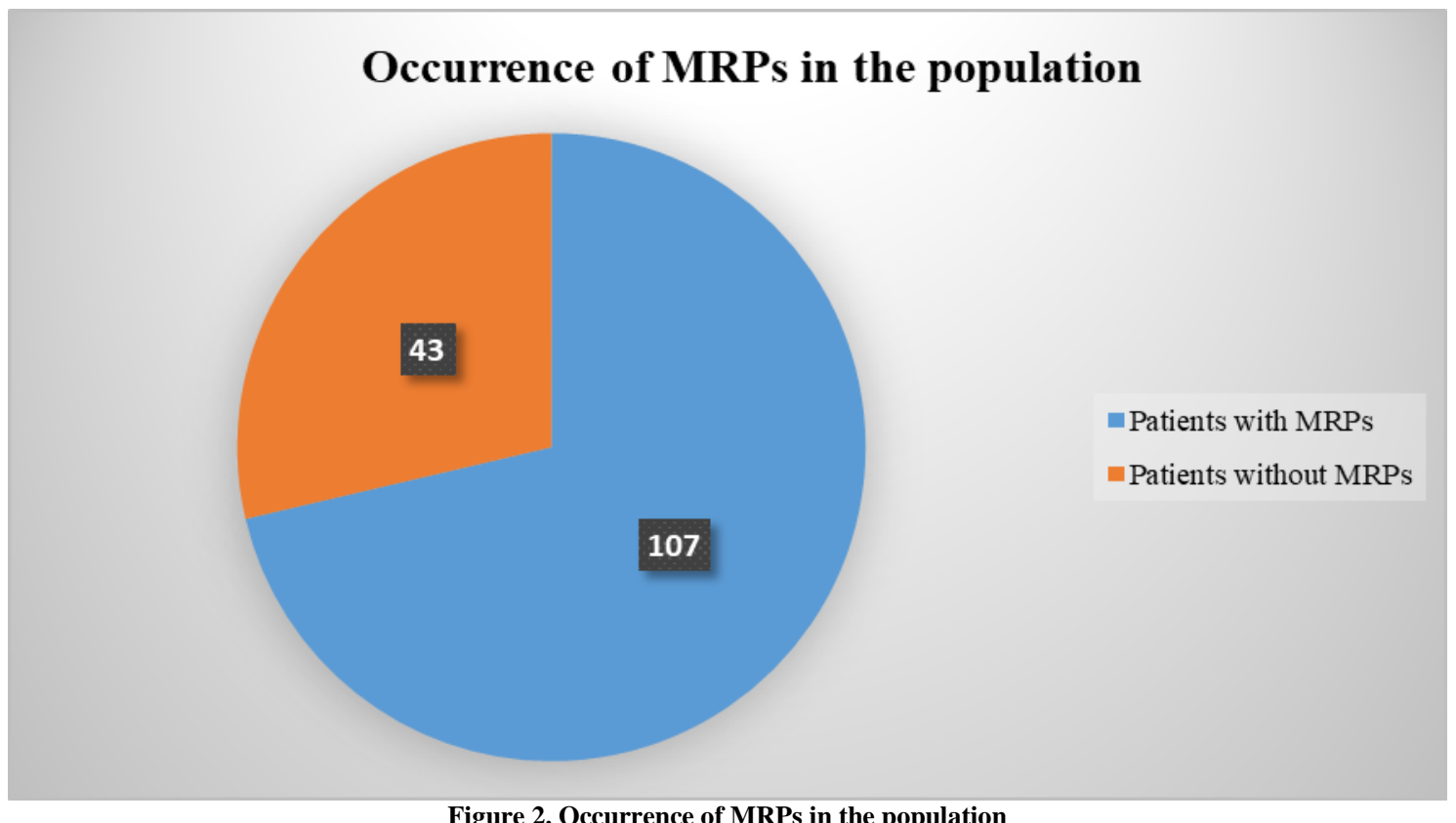

Table 2 shows the occurrence of MRPs among male and female population in detail and the percentage in each population where MRPs were identified.

\section{Class of Drugs Causing MRPs in Elderly Patients:}

From this study, it was found that drugs such as calcium channel blockers, beta blockers, ARB's, statins, diuretics, anti-hyperlipidaemics, oral hypoglycemic agents, antibiotics, bronchodilators, NSAIDS, anticoagulants, thyroid hormones, gastro protectants, anti-epileptic agents and dopamine agonists etc. were more frequently involved in causing MRPs. The important drug classes which were frequently involved in causing MRPs are shown in Figure 3. It shows the percentage of occurrence of MRPs in the 107 patients who were identified with MRPs.

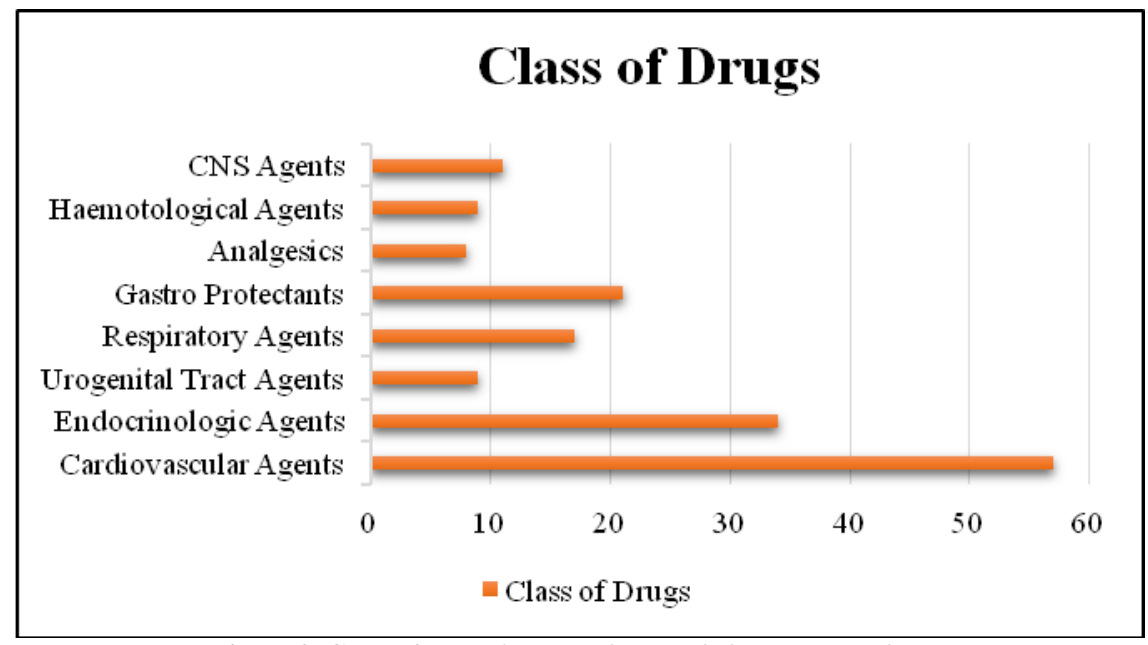

Figure 3. Class of drugs involved in MRP's in elderly patients.

\section{DISCUSSION}

Medication related problems are becoming a large public health concern as elderly population is associated with co- morbidities, poly-pharmacy \& use of specific drugs.

In the present study, 150 patients is either sex aged above 60 years have participated in the study. Out of the 150 
patients who participated in the study, 82 were males and 68 were females. A total of 107 patients were identified with MRPs from the total population. Among the population identified with MRPs, 56 were males and 51 were females. Most number of patients participated in the study belonged to the group agreed between $60-70$ years. A total of 76 patients who participated belonged to this group. A total of 196 MRPs were identified from 107 patients.

From the present study it was found that, patients who were treated with calcium channel blockers, beta-blockers, ARBs, statins, diuretics, anti-hyperlipidaemics, anticoagulants, anti-epileptic agents, etc. were more frequently involved in causing MRPs.

The drugs mostly causing MRPs belonged to the class of cardiovascular agents. That causes MRPs in about $57 \%$ of the population out of the 107 patients who were identified with MRPs. They were followed by endocrinologic agents (33\%), gastro-protectants $(21 \%)$, respiratory agents (17\%), CNS agents (11\%), hematological agents (9\%), urogenital tract agents (9\%), analgesics (8\%) and others.

A study by Gurwitz JH et al., which was conducted among elderly patients in ambulatory seeing found the occurrence of misery number of adverse events in patients treated with cardiovascular agents. ${ }^{[14]} \mathrm{A}$ similar sturdy was also conducted by Wincent MM et al., and it was found that MRPs occurred more frequently in patients who were treated with anti-diabetic agents and cardiovascular agents. ${ }^{[15]}$

The present study provided an extensive data on the class is drugs causing MRPs in the community settings of Dakshina Kannada. A large majority of the medication related problems can be solved by pharmacist interventions. [15] A community pharmacist can identify these MRPs by using comprehensive tools and can provide intervention to resolve \& prevent them.

\section{CONCLUSION}

The study showed that the incidence of MRPs are high in elderly and depends on the class of drugs with which the patient is being treated along with other factors. Cardiovascular agents were found to be causing the highest number of MRPs contributing to more than half of the MRPs. The results of the study demonstrated the need for a pharmacist \& concluded, that a large majority of the medication related problems can be solved by pharmacist intervention and lead to a better healthcare outcome.

\section{Acknowledgement: None}

\section{Conflict of Interest: None}

\section{Source of Funding: None}

\section{Ethical Approval: Approved}

\section{REFERENCES}

1. Van Mil JW, Horvat N, Westerlund T. PCNE Classification for Drug related problems. In $32^{\text {nd }}$ ESCP Symposium Pharmacists in the Health Care Team: Standards of Practice and Systems of Care. Valencia (Spain): ESCP 2003.

2. Hailu BY, Berhe DF, Gudina EK, Gidey K, Getachew M. Drug related problems in admitted geriatric patients: the impact of clinical pharmacist interventions. BMC geriatrics. 2020; 20(1): 1-8.

3. Starner CI, Gray SL, et al. Pharmacotherapy a Pathophysiologic Approach. 7th ed. New York: McGraw-Hill Medical; 2008. pp. 5766.

4. Ramanath KV, Nedumballi S. Assessment of Medication-Related Problems in Geriatric Patients of a Rural Tertiary Care Hospital. Journal of young pharmacists. 2012; 4(4): 273-8.

5. Lau E, Dolovich LR. Drug-related problems in elderly general practice patients receiving pharmaceutical care. International Journal of Pharmacy Practice. 2005; 13(3): 165-7.

6. Ingle GK, Nath A. Geriatric health in India: Concerns and solutions. Indian journal of community medicine: Official publication of Indian Association of Preventive \& Social Medicine. 2008; 33(4): 214-5. 
7. Silva C, Ramalho C, Luz I, Monteiro J, Fresco P. Drug-related problems in institutionalized, polymedicated elderly patients: opportunities for pharmacist intervention. International journal of clinical pharmacy. 2015; 37(2): 327-34.

8. Adusumilli PK, Adepu R. Drug related problems: an over view of various classification systems. Asian J Pharm Clin Res. 2014; 7(4): 7-10.

9. Ahmad A, Mast MR, Nijpels G, Elders P, Dekker J, Hugtenburg J. Identification of drug-related problems of elderly patients discharged from hospital. Patient Prefer Adherence. 2014; 8: 155-65.

10. Marušić S, Sičaja M, Neto PO, Franić M, Marinović I, Bačić-Vrca V. Adverse drug reactions in elderly patients following discharge from an internal medicine clinic. International journal of clinical pharmacology and therapeutics. 2014; 52: 906-9.

11. Roughead EE, Semple SJ. Medication safety in acute care in Australia:where are we now? Part 1: a review of the extent and causes of medication problems 2002-2008. Aust New Zealand Health Policy. 2009; 6: 18.

12. Stewart S, Pearson S, Luke CG, Horowitz JD. Effects of home-based intervention on unplanned readmissions and out-of-hospital deaths. J Am Geriatr Soc. 1998; 46: 174180.

13. Wilmer CM, Huiskes VJB, Natsch S, et al Drug-related problems in a clinical setting: a literature review and cross-sectional study evaluating factors to identify patients at risk European Journal of Hospital Pharmacy 2015; 22: 229-35.

14. Gurwitz JH, Field TS, Harrold LR, Rothschild J, Debellis K, Seger AC, et al. Incidence and Preventability of Adverse Drug Events Among Older Persons in the Ambulatory Setting. JAMA. 2003; 289(9): 1107-16.

15. Wincent MM, Potrilingam D, Anagha V, JACOB SC, Andhuvan G. Assessment of drug related problems in patients with chronic diseases in the general medicine units of a tertiary care hospital. Age. 2017; 54: 39 .

How to cite this article: Pradhan A, Benny F, Shabaraya AR. Identification of different class of drugs causing medication related problems in the elderly patients of Dakshina Kannada. International Journal of Research and Review. 2021; 8(8): 668-672. DOI: https://doi.org/10. 52403/ijrr.20210888 